\title{
Evaluation of serum/salivary levels of carnosine and cotinine in recurrent wheezing of young children with passive smoking
}

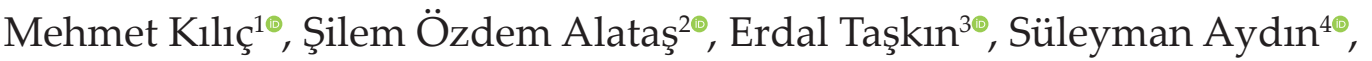 \\ Mehmet Onur Kaya ${ }^{5 \oplus}$ \\ Departments of ${ }^{1}$ Pediatric Allergy and Immunology, ${ }^{2}$ Pediatrics, ${ }^{3}$ Neonatology, ${ }^{4}$ Biochemistry and ${ }^{5}$ Biostatistics, Firat University \\ Faculty of Medicine, Elaziğ, Turkey.
}

\begin{abstract}
Background. Recurrent wheezing is common in young children, with a cumulative prevalence of up to $40 \%$ in the first 6 years of life. In this study, we aimed to evaluate the relationship between the number of wheezing episodes and the number of cigarettes smoked at home and serum / saliva cotinine and carnosine levels in children with recurrent wheezing.
\end{abstract}

Methods. This study was conducted with 80 young children with recurrent wheezing, aged between 1-4 years and 50 healthy control groups. Patient population was divided into three groups depending on the number of their exposure to cigarette smoke and wheezing attacks. Serum cotinine, saliva cotinine, serum carnosine, saliva carnosine, vitamin D levels were measured by using the ELISA method.

Results. A significant relationship for serum cotinine and saliva cotinine levels was found between groups $(\mathrm{p}<0.05)$. It was determined that as the number of exposure to cigarette smoke and number of wheezing episodes in young children with recurrent wheezing increased, the level of serum/saliva cotinine levels increased significantly, compared to the control group. In contrast, it was determined that as the number of exposure to cigarette smoke and number of wheezing episodes in young children with recurrent wheezing increased, serum/saliva carnosine levels decreased significantly, compared to the control group. In addition, a significant difference in serum vitamin D levels was found between healthy young children and young children with recurrent wheezing $(\mathrm{p}<0.05)$.

Conclusions. We think that the measurement of salivary cotinine is a useful and noninvasive marker to evaluate passive smoking exposure in the etiology of recurrent wheezing in young children.

Key words: recurrent wheezing, cotinine, carnosine, serum, saliva, vitamin D, exposure smoke.

Recurrent wheezing is common in young children, with a cumulative prevalence of up to $40 \%$ in the first six years of life. It is an important cause of diminished health-related quality of life in infancy. ${ }^{1}$ The etiology of wheezing is usually difficult to ascertain, and wheezing is not specific for asthma and can be due to viral infection or environmental exposure (e.g.,smoking). ${ }^{2}$

凶 Mehmet Kılıç

drmkilic@gmail.com

Received 23th October 2020, revised 9th December 2020, accepted 25th December 2020.
Children are commonly exposed to passive cigarette smoke at an early age. Children are one of the groups mostly affected by exposure to environmental cigarette smoke. As children breathe more frequently than adults, they inhale environmental cigarette smoke more often. In addition, children cannot protect themselves from exposure to cigarette smoke. ${ }^{3}$ Smoking during pregnancy has a devastating effect on the fetal lung and suppresses the development of airways. Passive smoking after birth has been reported to cause a decrease in ciliary movements, an increase in mucus production, impairment in lung functions, inflammation in 
the mucosa, degeneration in epithelial cells, and an increase in the incidence of lower respiratory tract infections. ${ }^{4}$

Two methods can be used to evaluate the exposure to passive cigarette smoke in children: a questionnaire answered by the parents and the measurement of saliva, urine, and serum cotinine levels. Studies have reported that the information given by parents about the exposure of their children to cigarette smoke does not correlate with the level of cotinine measured in children, and thus this information alone is not sufficient. 5,6 Measuring the cotinine level indicates recent smoking or passive exposure to cigarette smoke (e.g., 2-3 days). The half-life of cotinine in biological fluids (i.e., urine, serum, and saliva) is the same at 15-19 hours. Its halflife in children is higher than that in adults (65 h in neonates, $<18$ months 60 hours, $\geq 18$ months 40 hours). The cotinine levels in serum and saliva are similar, and urine / serum ratio is $5 / 6$. The measurement of cotinine in saliva and urine is preferred, especially in epidemiological studies, because it is not invasive and shows a relatively long duration of exposure. Although the cotinine values in urine change depending on age, renal functions are also affected by the amount of urine output and urine $\mathrm{pH}$. For this reason, measuring the level of cotinine in saliva is preferred. ${ }^{6}$

The lungs have an antioxidant system to minimize exposure to the oxidant, but due to the overproduction of oxidant molecules, this protective system falls short and damage occurs. An increase in reactive oxygen products caused by cigarette smoke exceeding the protective capacity of the oxidant defense system has been reported to cause oxidative damage in proteins, lipids, and DNA. ${ }^{7}$ Moreover, exposure to cigarette smoke causes a decrease in antioxidant levels. ${ }^{8}$ Also, it has been shown that levels of antioxidants are reduced in children with wheezing episodes. ${ }^{9}$ Carnosine, one of the antioxidant molecules, is endogenously synthesized by binding the amino acids $\beta$-alanine and L-histidine through a reaction catalyzed by carnosine synthase. Carnosine is found mainly in the kidneys, lungs, liver, and blood. Similar to many molecules synthesized from biological tissues, carnosine can pass through circulation and saliva. The antioxidant activity of carnosine was examined by Boldyrev et al. ${ }^{10}$ in the 1980s. The antioxidant activity of carnosine is mediated by different mechanisms, including metal ion chelation, scavenging of reactive oxygen radicals, and protection of the cell membrane from lipid peroxidation. ${ }^{10-12}$ In addition, there is an increasing awareness of the important role of vitamin $\mathrm{D}$ in the maintenance of general immune and respiratory health. The growing data suggests that vitamin D plays an important role in the lung development and it is discussed as a risk factor for respiratory infections andrecurrent wheezing. ${ }^{13,14}$

In this study, we aimed to evaluate the relationship between the serum/saliva cotinine and carnosine levels and the number of wheezing episodes and the number of cigarettes smoked at home in young children with recurrent wheezing.

\section{Material and Methods}

Eighty children aged 1-4 years with a diagnosis of recurrent wheezing and passive smoking were included in the study. The attacks of wheezing were diagnosed by a doctor. In addition, 50 healthy children who were not exposed to passive smoking at home were included in the control group. Cases with prematurity, malnutrition, cystic fibrosis, primary ciliary dyskinesia, bronchopulmonary dyskinesia, bronchiectasis, congenital anomalies of the respiratory system, chest deformity and interstitial lung diseases, gastroesophageal reflux, swallowing dysfunction, foreign body aspiration, immunodeficiency, malignancy, congenital heart disease, congenital syndromes, and chronic hematological, renal, hepatic, and neurological diseases were not included in the study and the control group. Detailed questionnaire data were obtained from parents of all the young children participating in the study. The questionnaire consisted of questions 
about the young children (age, gender, modes of delivery, birth weight, breastfeeding duration, sibling attending school or nursery, number of wheezing episodes diagnosed by the doctor), his/her family (number of peoples living at home, maternal education, age of mother at birth, father education, monthly income status, the number of cigarettes smoked daily by individuals living at home while the child is at home, mother's smoking during pregnancy, mother's smoking in postpartum period, father's smoking, smoking by other members of the household).

The amount of passive smoking was defined as the number of cigarettes smoked daily by individuals living at home (mother, father, siblings, and other members of the family) while the child is at home. The number of cigarettes smoked when they are away from the child during the day (e.g., workplace, outdoor environment) was not included in this grouping. The definition of recurrent wheezing was accepted as at least $\geq 4$ wheezing episodes requiring bronchodilator medication (salbutamol). These patients were classified according to the number of episodes they had experienced in the previous year: group I, 4-6 episodes; group II, 7-10 episodes; and group III, > 10 episodes. Moreover, the patients with recurrent wheezing were divided into three groups according to the number of cigarettes smoked daily at home: group $\mathrm{A}, \leq 5$; group $\mathrm{B}$, 6-9; and group $C, \geq 10$ cigarettes.

To clarify the etiology of wheezing in all patients included in the study, complete blood count, eosinophil count in peripheral blood, serum immunoglobulin levels, evaluation of lymphocyte subgroups, sweat test, purified protein derivative test, chest radiography, QuantiFERON test, gastroesophageal reflux scintigraphy, fx5-specific IgE, Phadiatop test, and food and inhaled allergens skin prick test were performed. In case of an indication, 24-h esophageal $\mathrm{pH}$ monitoring, barium esophagusstomach-duodenum radiography, analysis of acid-resistant bacteria and hemosiderin- loaded macrophage in fasting gastric juice, IgG subgroup measurement, tuberculosis culture, bronchoscopy, echocardiography, measurement of alpha-1 antitrypsin, electron microscopic examination, nasal biopsy, and radiological imaging studies, such as high resolution computed tomography and thorax magnetic resonance were also performed.

The serum carnosine and cotinine levels were analyzed in $1 \mathrm{cc}$ venous blood samples remaining from the blood taken from the cases in the study and control groups for routine tests. The venous blood samples were centrifuged and stored at $-80^{\circ} \mathrm{C}$. In addition, the saliva was obtained from the patients in the study and control groups to analyze the cotinine and carnosine levels. All saliva collections were performed by suctioning saliva from the buccal cavity in the infant's mouth with a soft plastic transfer pipette, attempting to collect $0.5-1 \mathrm{~mL}$ of saliva. All saliva specimens were performed when the child's mouth was free of food or milk. After centrifugation for $5 \mathrm{~min}$ at $2000 \mathrm{rpm}$, the samples were stored at $-80^{\circ} \mathrm{C}$. The serum and saliva cotinine levels were measured using an ELISA kit according to the manufacturer's instructions. The detailed description of the sample collection and analysis has been published elsewhere. ${ }^{15}$ In addition, serum $25(\mathrm{OH})$ D3 level was studied from the blood taken for routine biochemical tests in both the control and wheezing groups. Serum $25(\mathrm{OH})$ D3 levels were analyzed with chemiluminescent microparticle immunoassay (CMIA) (ARCHITECT c8000, Abbott, Abbott Park, Illinois, USA). The $25(\mathrm{OH})$ D3 level above $30 \mathrm{ng} / \mathrm{ml}$ is accepted sufficient; the level between 20 and $30 \mathrm{ng} / \mathrm{ml}$ insufficient; $<20 \mathrm{ng} / \mathrm{ml}$ deficient and under $10 \mathrm{ng} / \mathrm{ml}$ is extremely deficient.

The necessary approval for the study was obtained from the clinical research ethics committee of Firat University (Ethical board date/number: 05.09.2013/03-07). The families invited to participate in the study were informed about the research, and their written consent was obtained. 


\section{Statistical methods}

All data were analyzed using the SPSS version 22.0 (IBM, Chicago, IL, USA) program. The compliance of the continuous variables determined by the measurement of a normal distribution was evaluated using the ShapiroWilk test. Nonparametric tests were used to analyze the data. The results were given as the median (minimum-maximum). The MannWhitney $U$ test was used for the comparison of the mean values, the Kruskal-Wallis test for the comparison of more than two groups, the post-hoc Dunn test with Bonferroni correction for pairwise comparisons, and the Pearson chisquare test for the comparison of percentages. The cutoff points and the rates of sensitivity and specificity were evaluated with the receiver operating characteristic (ROC) analysis to determine the diagnostic power of the quantitative data measured. A p-value of $<0.05$ was considered statistically significant.

\section{Results}

Twenty-eight (35\%) girls and $52(65 \%)$ boys, with an overall mean age of 25.5 (12-46) months, had a history of recurrent wheezing episodes. In the control group, 22 (44\%) were girls and $28(56 \%)$ were boys, with an overall mean age of 24 (12-47) months. No difference was found between the patient and control groups in terms of age and gender ( $p>0.05)$. In the wheezing group, the levels of serum cotinine (2.01 $[0.78-3.44] \mathrm{pg} / \mathrm{ml})$, salivary cotinine $(2.00$ [0.66-3.04] pg/ml), serum carmosine (129 [96$191] \mathrm{ng} / \mathrm{ml}$ ), salivary carnosine (124 [93-186] ng/ $\mathrm{ml})$, and vitamin D (19.5 [3-63] ng / ml) were determined as indicated. In the control group, the levels of serum cotinine $(0.59$ [0.18-1.61] pg/ $\mathrm{ml})$, salivary cotinine $(0.46[0.06-1.28] \mathrm{pg} / \mathrm{ml})$, serum carmosine (166 [96-192] ng/ml), salivary carnosine (148 [103-190] ng/ml), and vitamin D (24.6 [11-52] $\mathrm{ng} / \mathrm{ml})$ were determined as indicated.

A statistically significant difference was found between the recurrent wheezing and control groups in terms of serum vitamin D, serum/ salivary cotinine, and serum/salivary carnosine levels $(\mathrm{p}<0.05)$ (Table I). A statistically significant difference was also found between the recurrent wheezing and control groups in terms of total IgE levels, maternal age at birth, duration of breastfeeding, maternal education, and number of individuals living at home $(\mathrm{p}<$ 0.05). However, there was no difference between the patient and control groups in terms of birth weight, absolute eosinophil count in peripheral blood, history of siblings attending school or nursery, family income, and father's education level $(\mathrm{p}>0.05)$ (Table I).

Among the 32 patients in group I, 10 (31.3\%) were girls and $22(68.8 \%)$ were boys, with an overall average age of $24(12-44)$ months. Among the 30 patients in group II, 12 (40\%) were boys and $18(60 \%)$ were girls, with an overall average age of $30(15-46)$ months. Among the 18 patients in group III, $6(33.3 \%)$ were girls and 12 $(66.7 \%)$ were boys, with an overall average age of 33 (12-46) months. No statistically significant difference was found between the groups in terms of gender $(p>0.05)$ (Table II). However, a weak relationship was found between group I and group II when the groups were evaluated in terms of age. The number of wheezing episodes increased with age $(\mathrm{p}=0.01, \mathrm{r}=0.28)$.

When the children in the wheezing group were compared in terms of serum and salivary cotinine levels, a statistically significant difference was found only between groups I and III ( $\mathrm{p}=0.002, \mathrm{p}=0.001$, respectively) (Table II, Fig. 1). In addition, when the cases in the wheezing group were compared in terms of the number of cigarettes smoked daily at home, a significant difference was found between groups I and II and between groups I and III ( $\mathrm{p}$ $=0.001, \mathrm{p}=0.0001$, respectively).

When the wheezing groups were compared in terms of father's smoking and mother's smoking during pregnancy, during the breastfeeding period, and after the breastfeeding period, no statistical difference was found $(p>0.05)$. 
Table I. Comparison of demographic and laboratory characteristics of the patient and control groups.

\begin{tabular}{|c|c|c|c|}
\hline Features & $\begin{array}{l}\text { Control group } \\
\text { (n: 50) }\end{array}$ & $\begin{array}{l}\text { Wheezing group } \\
\text { (n: 80) }\end{array}$ & $\mathrm{p}$ value \\
\hline Age (months) * & $24(12-47)$ & $25.5(12-46)$ & 0.08 \\
\hline \multicolumn{4}{|l|}{ Gender n $(\%)$} \\
\hline Girl & $22(44 \%)$ & $28(35 \%)$ & \multirow[t]{2}{*}{0.3} \\
\hline Boy & $28(56 \%)$ & $52(65 \%)$ & \\
\hline Absolute eosinophil count $\left(/ \mathrm{mm}^{3}\right)^{*}$ & $205(40-890)$ & $260(10-3230)$ & 0.2 \\
\hline \multicolumn{4}{|l|}{ Total IgE level (IU / ml) } \\
\hline Normal & $42(84 \%)$ & $35(43.8 \%)$ & \multirow[t]{2}{*}{0.03} \\
\hline High & $8(16 \%)$ & $45(56.3 \%)$ & \\
\hline Vitamin D level (ng / ml)* & $24.6(11-52)$ & $19.5(3-63)$ & 0.005 \\
\hline Serum cotinine level $(\mathrm{pg} / \mathrm{ml}) *$ & $0.59(0.18-1.61)$ & $2.01(0.78-3.44)$ & 0.0001 \\
\hline Saliva cotinine level $(\mathrm{pg} / \mathrm{ml})^{*}$ & $0.46(0.06-1.28)$ & $2.00(0.66-3.04)$ & 0.0001 \\
\hline Serum carnosine level (ng / ml) & $166(96-192)$ & $129(96-191)$ & 0.0001 \\
\hline Saliva carnosine level $(\mathrm{ng} / \mathrm{ml}) *$ & $148(103-190)$ & $124(93-186)$ & 0.0001 \\
\hline Age of mother at birth (years) ${ }^{*}$ & $29(21-40)$ & $25(20-39)$ & 0.0001 \\
\hline \multicolumn{4}{|l|}{ Monthly income status (dollars) n (\%) } \\
\hline$<300 \$$ & $19(38 \%)$ & $23(28.7 \%)$ & \multirow[t]{5}{*}{0.1} \\
\hline $300-499 \$$ & $24(48 \%)$ & $51(63.7 \%)$ & \\
\hline $500-999 \$$ & $6(12 \%)$ & $3(3 \%)$ & \\
\hline $1000-1499 \$$ & $1(2 \%)$ & $1(1.3 \%)$ & \\
\hline$>1500 \$$ & - & $2(2.5 \%)$ & \\
\hline \multicolumn{4}{|l|}{ Maternal education n (\%) } \\
\hline Primary education & $35(70 \%)$ & $70(87.5 \%)$ & \multirow[t]{3}{*}{0.004} \\
\hline High school & $15(30 \%)$ & $7(8.8 \%)$ & \\
\hline University & - & $3(3.8 \%)$ & \\
\hline \multicolumn{4}{|l|}{ Father education $\mathrm{n}(\%)$} \\
\hline Primary education & $36(72 \%)$ & $56(70 \%)$ & \multirow[t]{3}{*}{0.9} \\
\hline High school & $12(24 \%)$ & $21(26.3 \%)$ & \\
\hline University & $2(4 \%)$ & $3(3.8 \%)$ & \\
\hline \multicolumn{3}{|l|}{ Breastfeeding duration $\mathrm{n}(\%)$} & \multirow[t]{4}{*}{0.007} \\
\hline No & - & $6(7.5)$ & \\
\hline$<6$ months & $11(22 \%)$ & $32(46 \%)$ & \\
\hline$\geq 6$ months & $39(78 \%)$ & $42(52.5)$ & \\
\hline \multicolumn{4}{|l|}{ Sibling attending school or nursery n (\%) } \\
\hline Yes & $44(88 \%)$ & $65(81.3)$ & \multirow[t]{2}{*}{0.3} \\
\hline No & $6(12 \%)$ & $15(18.7)$ & \\
\hline \multicolumn{4}{|l|}{ Birth weight $(\mathrm{kg})$} \\
\hline$\leq 2500$ & $9(18 \%)$ & $23(28.1 \%)$ & \multirow[t]{2}{*}{0.06} \\
\hline$>2500$ & $41(82 \%)$ & $57(71.3 \%)$ & \\
\hline \multicolumn{4}{|l|}{ Modes of delivery n (\%) } \\
\hline Vaginal delivery & $40(80 \%)$ & $62(77.5 \%)$ & \multirow[t]{2}{*}{0.1} \\
\hline Cesarean section & $10(20 \%)$ & $18(22.5 \%)$ & \\
\hline Number of peoples living at home * & $4(3-6)$ & $5(3-7)$ & 0.002 \\
\hline
\end{tabular}

* Median (minimum-maximum) 


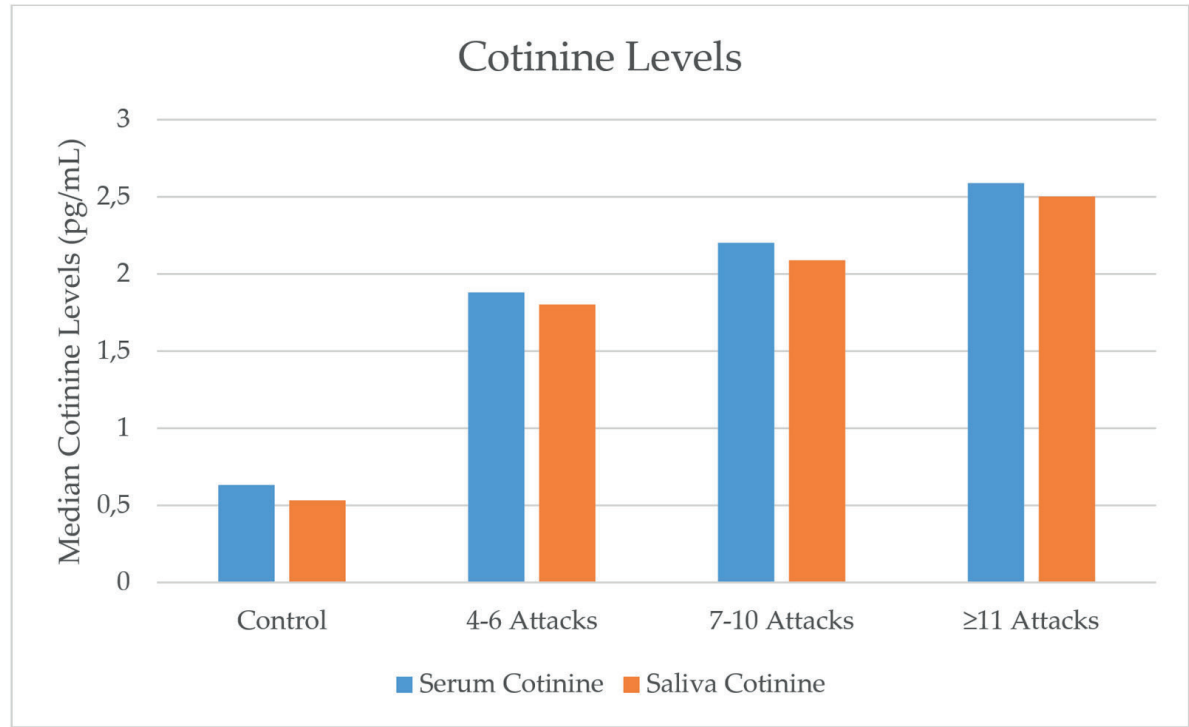

Fig. 1. Comparison of serum / salivary cotinine levels between control group and group I-II-III.

However, a statistically significant difference was found $(\mathrm{p}=0.003)$ when the wheezing group was evaluated in terms of the smoking history of other family members. We found that in $22(27.5 \%)$ of the 80 patients with wheezing, household members other than parents at home were smoking. In four of the cases $(18.2 \%)$, other family members except both parents smoked at home, and in 18 cases (81.8), the mother and/or father of the patients smoked together with the other family members. In addition, when the wheezing groups were compared in terms of serum and salivary carnosine levels, a statistically significant difference was found only between groups I and III ( $p=0.01, p=0.01$, respectively) (Table II, Fig. 2).

When groups A, B, and C, which were classified according to the number of cigarettes smoked daily that the child was exposed to at home, were compared in terms of serum cotinine levels, a statistical difference was found between groups $\mathrm{A}$ and $\mathrm{B}$, between groups $\mathrm{A}$ and $\mathrm{C}$, and between groups $B$ and $C(p=0.03, p=0.0001, p=$ 0.01 , respectively). In terms of cotinine levels in saliva, a statistically significant difference was found between groups $A$ and $C$ and between groups $B$ and $C(p=0.0001, p=0.01$, respectively) (Table III, Fig. 3).
When the groups classified according to the number of cigarettes smoked daily that the child was exposed to at home were evaluated in terms of serum carnosine levels, a statistically significant difference was found between groups $\mathrm{A}$ and $\mathrm{B}$, between groups $\mathrm{A}$ and $\mathrm{C}$, and between groups $B$ and $C(p=0.04, p=0.0001, p=$ 0.01 , respectively). When the salivary carnosine levels were evaluated, a statistically significant difference was found between groups $\mathrm{A}$ and $\mathrm{C}$ and between groups B and C ( $\mathrm{p}=0.0001, \mathrm{p}$ $=0.0001$, respectively) (Table III). When the groups classified according to the number of cigarettes smoked daily that the child was exposed to at home were evaluated in terms of mother's education, father's education, monthly income of the family, and number of people living at home, no statistically significant difference was found $(\mathrm{p}=0.2, \mathrm{p}=0.3, \mathrm{p}=0.7, \mathrm{p}$ $=0.5$, respectively).

To predict the exposure to passive smoking in children with a history of recurrent wheezing based on the ROC curve analysis for the serum cotinine level, we used the cutoff value of $>$ $1.26 \mathrm{pg} / \mathrm{ml}$, with $97.5 \%$ sensitivity and $98 \%$ specificity. Moreover, the cutoff value for the salivary cotinine level was $>1.18 \mathrm{pg} / \mathrm{ml}$, with $96.2 \%$ sensitivity and $98 \%$ specificity. 
Table II. Comparison of demographic and laboratory characteristics of cases classified according to the number of wheezing attacks.

\begin{tabular}{|c|c|c|c|c|}
\hline Features & Group I (n: 32) & Group II (n: 30) & Group III (n: 18) & $\mathrm{p}$ value \\
\hline Age (month)* & $24(12-44)$ & $30(15-46)$ & $33(12-46)$ & $0.01^{* *}$ \\
\hline \multicolumn{5}{|l|}{ Gender n (\%) } \\
\hline Girl & $10(\% 31.3)$ & $12(\% 40)$ & $6(\% 33.3)$ & \multirow[t]{2}{*}{0.8} \\
\hline Boy & $22(\% 68.8)$ & $18(\% 60)$ & $12(\% 66.7)$ & \\
\hline Serum vitamin D level $(\mathrm{ng} / \mathrm{ml})^{*}$ & $19.3(3-63)$ & $19.1(3-45)$ & $20(7-43)$ & 0.8 \\
\hline Serum cotinine level $(\mathrm{pg} / \mathrm{ml}) *$ & $1.93(0.78-2.92)$ & $2.09(0.78-3.31)$ & $2.84(1.66-3.44)$ & $0.002^{* * *}$ \\
\hline Saliva cotinine level $(\mathrm{pg} / \mathrm{ml}) *$ & $1.86(0.69-2.91)$ & $2.0(0.66-3.04)$ & $2.73(1.60-3.01)$ & $0.001^{* * *}$ \\
\hline $\begin{array}{l}\text { The number of cigarettes smoked at home } \\
\text { (pieces / day)* }\end{array}$ & $4(2-11)$ & $9(2-40)$ & $15(3-30)$ & $0.001^{* *}$ \\
\hline Number of peoples living at home* & $5(4-7)$ & $5(3-7)$ & $5(3-6)$ & 0.9 \\
\hline \multicolumn{5}{|l|}{ Maternal smoking during pregnancy n (\%) } \\
\hline No & $27(87.1 \%)$ & $29(80.6 \%)$ & $9(69.2 \%)$ & \multirow[t]{2}{*}{0.3} \\
\hline Yes & $4(12.9 \%)$ & $7(19.4 \%)$ & $4(30.8 \%)$ & \\
\hline \multicolumn{5}{|l|}{$\begin{array}{l}\text { Mother's smoking during breastfeeding } \\
\text { period } \mathrm{n}(\%)\end{array}$} \\
\hline No & $23(74.2 \%)$ & $24(66.7 \%)$ & $8(61.5 \%)$ & \multirow[t]{2}{*}{0.6} \\
\hline Yes & $8(25.8)$ & $12(33.3 \%)$ & $5(38.5 \%)$ & \\
\hline \multicolumn{5}{|l|}{$\begin{array}{l}\text { Mother's smoking after breastfeeding } \\
\text { period } \mathrm{n}(\%)\end{array}$} \\
\hline No & $20(64.5 \%)$ & $23(63.9 \%)$ & $6(46.2 \%)$ & \multirow[t]{2}{*}{0.4} \\
\hline Yes & $11(35.5 \%)$ & $13(36.1 \%)$ & $7(53.8 \%)$ & \\
\hline \multicolumn{5}{|l|}{ Father's smoking n (\%) } \\
\hline No & $7(22.6 \%)$ & $6(16.7 \%)$ & $2(15.4 \%)$ & \multirow[t]{2}{*}{0.7} \\
\hline Yes & $24(77.4 \%)$ & $30(83.3 \%)$ & $11(84.6 \%)$ & \\
\hline \multicolumn{5}{|l|}{ Smoking of other family members $n(\%)$} \\
\hline No & $27(87.1 \%)$ & $23(63.9 \%)$ & $7(53.8 \%)$ & \multirow[t]{2}{*}{0.003} \\
\hline Yes & $4(12.9 \%)$ & $13(36.1 \%)$ & $6(46.2 \%)$ & \\
\hline Serum carnosine level $(\mathrm{ng} / \mathrm{ml})^{*}$ & $131(118-191)$ & 133.5(96-165) & $120(108-161)$ & $0.01^{* * *}$ \\
\hline Saliva carnosine level $(\mathrm{ng} / \mathrm{ml}) *$ & $128(110-186)$ & $126(93-146)$ & $118(100-141)$ & $0.01^{* * *}$ \\
\hline
\end{tabular}

\section{Discussion}

Various risk factors have been identified for recurrent wheezing in the first year of life. These risk factors may include gestational age, maternal age at birth, type of delivery, mother's smoking during pregnancy and postnatal period, exposure to cigarette smoke at home, environmental air pollution, breastfeeding duration, number of people living in the family, place of residence, male gender, going to nursery, viral respiratory tract infections, socioeconomic status, exposure to allergens, use of antibiotics or paracetamol, feeding animals at home, and history of atopic dermatitis. ${ }^{16-20}$

In our study, we did not find a statistically significant difference between the wheezing group and the control group in terms of age, gender, presence of siblings attending school or 


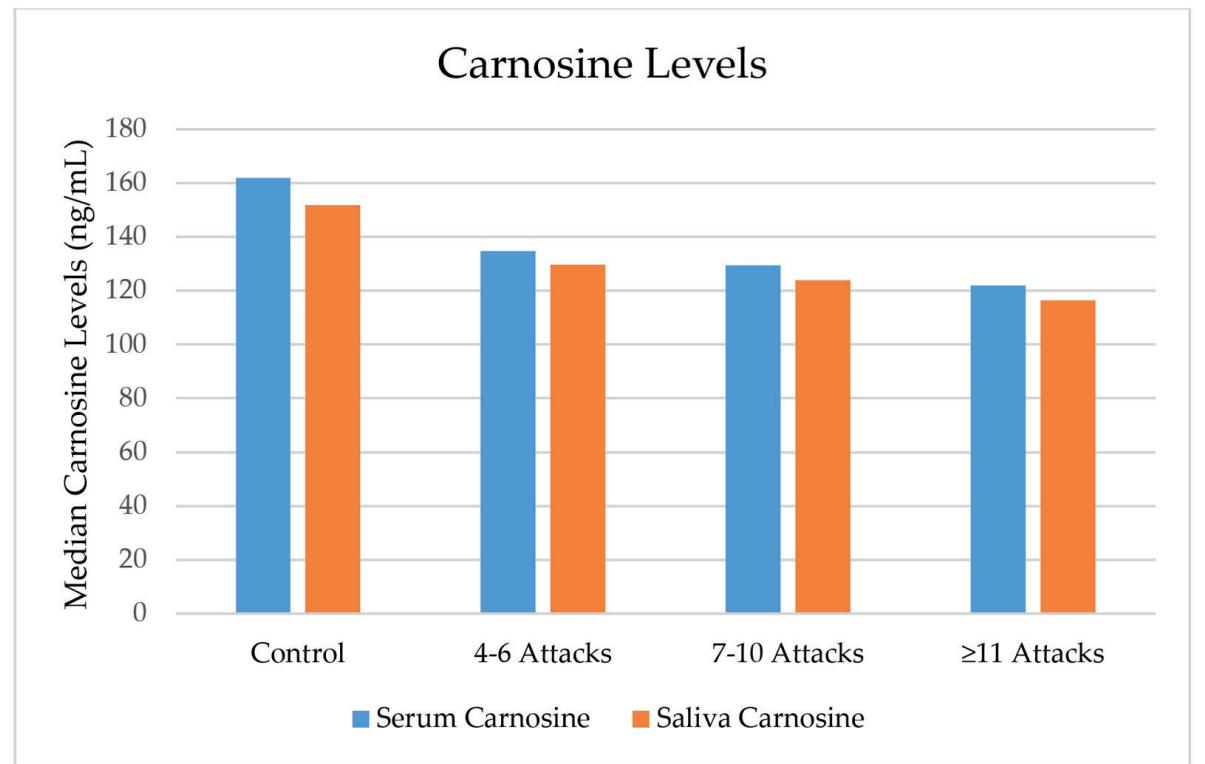

Fig. 2. Comparison of serum/salivary carnosine levels between control group and group I-II-III.

Table III. Comparison of serum/salivary cotinine and carnosine levels between control group and groups A-B-C.

\begin{tabular}{lccccl}
\hline Features & Control group & Group A (n: 32) & Group B (n: 23) & Group C (n: 25) & p value \\
\hline $\begin{array}{l}\text { Serum cotinine level } \\
(\mathrm{pg} / \mathrm{ml}) \neq\end{array}$ & $0.59(0.18-1.61)$ & $1.78(0.78-2.20)$ & $2.05(1.28-2.92)$ & $2.85(1.48-3.44)$ & $0.03^{*}$ \\
& & & & & $0.0001^{* *}$ \\
& & & & $0.01^{* * *}$ \\
& & & & $0.0001^{* * * *}$ \\
$\begin{array}{l}\text { Saliva cotinine level } \\
(\mathrm{pg} / \mathrm{ml}) \neq\end{array}$ & $0.46(0.06-1.28)$ & $1.72(0.66-2.12)$ & $2.00(1.31-2.91)$ & $2.76(1.18-3.04)$ & $0.0001^{* *}$ \\
& & & & & $0.01^{* * *}$ \\
$\begin{array}{l}\text { Serum carnosine level } \\
\text { (ng/ml) } \neq\end{array}$ & $166(96-192)$ & $138(125-165)$ & $128.5(120-191)$ & $119.5(96-161)$ & $0.04^{*}$ \\
& & & & & $0.0001^{* *}$ \\
& & & & & $0.01^{* * *}$ \\
$\begin{array}{l}\text { Saliva carnosine level } \\
\text { (ng/ml) } \neq\end{array}$ & $148(103-190)$ & $129(110-148)$ & $128(118-186)$ & $118(93-146)$ & $0.0001^{* *}$ \\
& & & & & $0.0001^{* * *}$ \\
\hline
\end{tabular}

\# Median (minimum-maximum)

* Comparison of group IV and V

** Comparison of group IV and VI

*** Comparison of group V and VI

**** Comparison of control and group IV, V, VI

kindergarten, birth weight, birth type, monthly income of the family, father's education status, and absolute eosinophil count. However, we found a statistically significant difference between the wheezing group and the control group in terms of breastfeeding period time, number of people living at home, maternal education level, maternal age at birth, and total IgE level. Exposure to passive smoking increases mucus production in the lungs up to seven 


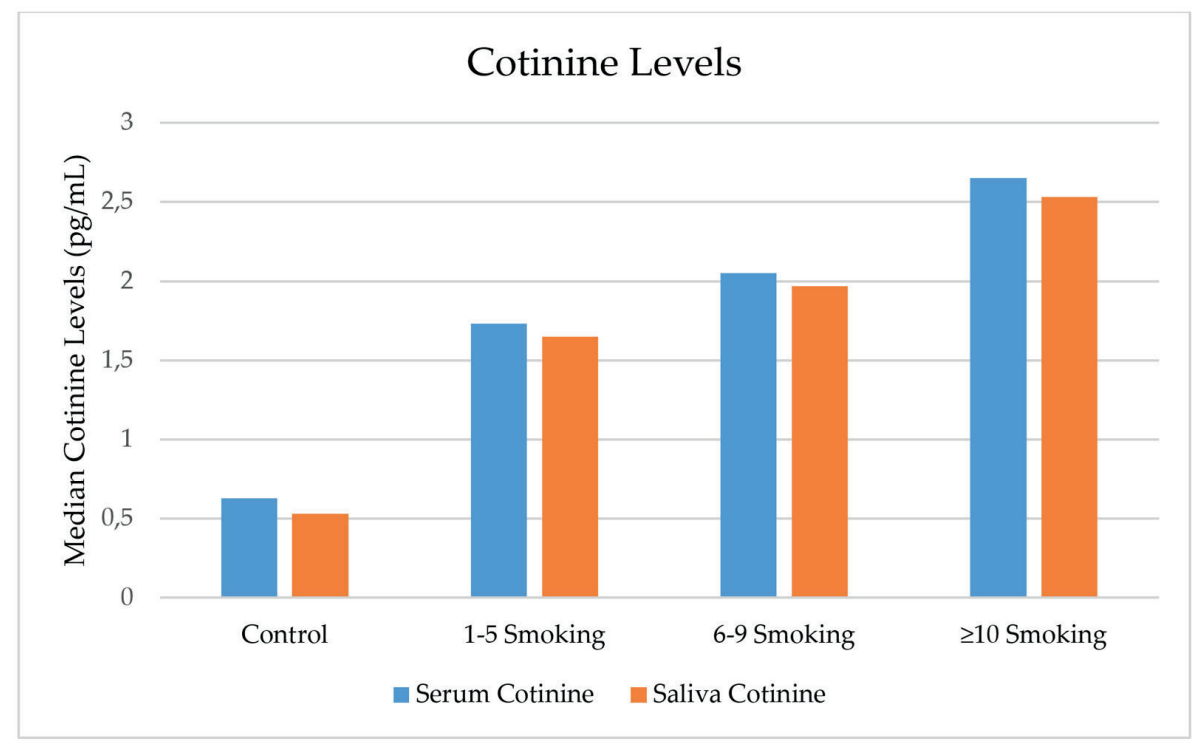

Fig. 3. Comparison of serum / salivary cotinine levels between control group and group A-B-C.

times, causing a decrease in ciliary movements and an increase in white blood cell count, total and specific IgE production, and eosinophil count in the blood. In addition, previous studies consistently linked younger maternal age with an increased risk of wheezing in childhood, suggesting that this could be explained by both social and biological factors. ${ }^{17,18}$ Moreover, Caudri et al. ${ }^{19}$ found a significant decrease in the frequency of wheezing in breastfed children. In our study, we found that the patients in the wheezing group were breastfed for a lesser time period than those in the control group and that the maternal age at birth was lower than that in the control group. Benicio et al. ${ }^{20}$ reported that a crowded home environment and poor socio-economic conditions are risk factors for recurrent wheezing. In our study, we did not find a difference between the wheezing and the control group in terms of monthly income of the family, but we found that more people were living at home with the children in the wheezing group. Unfortunately, we were unable to assess parental asthma or atopy history among risk factors for wheezing in young children. This, in assessing risk factors of recurrent wheezing can also be considered as a limitation.

There are some studies investigating the relationship between wheezing and vitamin D.
Demirel et al. ${ }^{21}$ detected lower vitamin $\mathrm{D}$ levels in children with recurrent wheezing than the controls. In addition, in many studies it has been reported that low levels of vitamin D may be a risk factor for recurrent wheezing. ${ }^{22,23}$ Similarly, we found significantly lower vitamin D levels in children with recurrent wheezing compared to the control group.

It has been reported that there is an increase in the frequency of cough, wheezing, and respiratory tract infections in children exposed to cigarette smoke at home and that this increase is directly proportional to the number of cigarettes smoked. ${ }^{24-26}$ Small children are particularly affected by their mothers' smoking. ${ }^{24,27}$ Epidemiological studies have reported that children are exposed to second-hand smoking because they stay with their parents for longer periods of time, and thus they experience respiratory diseases more frequently and severely. ${ }^{24,27}$ Atay et al. ${ }^{28}$ shown that the frequency of bronchiolitis was significantly higher in patients living in smoking homes. They also found that breathing second-hand smoke, living in a crowded house and heating with a stove were factors affecting the severity of bronchiolitis in patient. In our study, we did not find any statistical difference between the groups classified according to 
the number of wheezing episodes in terms of mother's smoking status during pregnancy, during the breastfeeding period, and after the breastfeeding period, and the father's smoking at home. However, we found a statistically significant difference between the groups classified according to the number of wheezing episodes in terms of smoking at home among other members of the family. We also found a difference between the wheezing groups in terms of the number of cigarettes smoked daily at home. As the number of cigarettes smoked at home increased, the number of wheezing episodes experienced by children increased. These findings indicate that exposure to cigarette smoke has an important place in the etiology of wheezing. In our study, we found that smoking by the mother and/or father and other members of the household increased the number of cigarettes smoked daily in the house, thus increasing the intensity of exposure of children to cigarette smoke in the house. This is supported by our finding that only four $(18.2 \%)$ homes had both mother and father who did not smoke, whereas the other members of the household were smokers. Conversely, in 18 cases $(81.8 \%)$, the mother and/or father smoked together with the other members of the household. In a study conducted in China, a positive relationship was found between the number of people who smoke at home and the hospitalization of children due to respiratory infections. ${ }^{29}$ Mannino et al. ${ }^{30}$ reported that children living with crowded families with low income levels and in small houses with fewer rooms were more likely to be exposed to passive smoking.

Irvine et al. $^{31}$ revealed a positive correlation between the number of cigarettes smoked at home and the number of people who smoked at home and the cotinine levels in children. In Sweden, the cotinine levels were measured in the serum, saliva, and urine samples of 2,684 children exposed to passive smoking. The cotinine values in urine, blood, and saliva of children whose both parents smoked were found to be higher than those of children who were not exposed to passive smoking. The respiratory symptoms of these children were detected at a higher frequency compared with other children. ${ }^{32}$ Chang et al. ${ }^{33}$ measured the salivary cotinine levels of children who presented to the emergency department and were diagnosed with wheezing. This study showed that measuring the level of cotinine in saliva was a valuable test to monitor the prevalence and intensity of passive exposure to cigarette smoke at home in wheezing children under four years of age. Moreover, the cotinine levels in saliva and serum were similar in children under the age of four years and were significantly correlated with each other. In our study, similar to the literature, we found that as the number of cigarettes smoked daily at home increased, the serum and saliva cotinine levels also increased. In the groups classified according to the number of wheezing episodes, we found that as the number of wheezing episodes increased, the serum and salivary cotinine levels also increased. The serum and salivary cotinine levels we measured to evaluate exposure to second-hand smoking at home were similar, with a positive correlation between them. In children with a history of recurrent wheezing episodes, the cutoff values for serum and salivary cotinine levels were $>1.26 \mathrm{pg} / \mathrm{mL}$ and $>1.18 \mathrm{pg} / \mathrm{ml}$, respectively. In light of these results, examining the level of cotinine in saliva, which is a noninvasive method, to evaluate passive smoking exposure in young children presenting with recurrent wheezing is recommended.

The carnosine has been proven to scavenge reactive oxygen species. Aside from its antioxidant properties, carnosine protects the cell membrane from lipid peroxidation. The function of most antioxidants is to prevent the entry of free oxygen radicals into tissues. However, if the oxidant molecules overcome this initial defense, these antioxidant molecules are not effective. The most important feature that distinguishes carnosine from other antioxidants is that it can also be protective at the cellular level, as it functions in the cytosol. Therefore, 
it protects the tissues from a second oxidant effect. Owing to these properties, carnosine stands out among other antioxidants. ${ }^{7,8}$ In our study, there was a negative correlation between the serum/salivary carnosine levels and the number of cigarette exposure. Moreover, as the number of wheezing episodes increased, the serum/salivary carnosine levels of the patients significantly decreased. A positive correlation was found between the saliva and serum carnosine levels. In our patients, the possible reason for the decrease in carnosine levels as the number of wheezing episodes increased is related to the utilization of carnosine to reduce oxidant molecules.

This study has several limitations. First, the patient and control groups had a limited number of cases. Moreover, the serum/salivary cotinine level together with the urine cotinine level were not measured. Second, the total antioxidant capacity of the patients in the patient and control groups were not measured. Third, the antioxidant properties of carnosine and the changes due to histopathological oxidative stress at the cellular and tissue levels were not demonstrated.

In conclusion, we found that the serum and salivary cotinine levels increased in parallel with each other in the assessment of passive smoking exposure in young children. Therefore, the measurement of salivary cotinine is a useful and noninvasive marker to evaluate passive smoking exposure in the etiology of recurrent wheezing in young children. Moreover, the serum/salivary carnosine levels decreased in young children as a result of recurrent episodes of wheezing and exposure to second-hand smoking. However, we consider that these results we obtained for carnosine should be investigated in future studies.

\section{Author contribution}

The authors confirm contribution to the paper as follows: study conception and design: Mehmet Kılıç, Erdal Taşkın; data collection: Şilem Özdem Alataş; analysis and interpretation of results: Mehmet Kılıç, Şilem Özdem Alataş, Süleyman Aydın, Erdal Taşkın, Mehmet Onur Kaya; draft manuscript preparation: Mehmet Kılıç, Erdal Taşkın. All authors reviewed the results and approved the final version of the manuscript.

\section{Ethical approval}

All procedures performed in studies involving human participants were in accordance with the ethical standards of the clinic.

The necessary approval for the study was obtained from the clinical research ethics committee of Firat University (Ethical board date/number: 05.09.2013/03-07). The families invited to participate in the study were informed about the research, and their written consent was obtained.

\section{Source of funding}

No financial conflicts to disclose.

\section{Conflict of interest}

The authors declare that they have no conflict of interests.

\section{REFERENCES}

1. Alvarez-Alvarez I, Niu H, Guillen-Grima F, Aguinaga-Ontoso I. Meta-analysis of prevalence of wheezing and recurrent wheezing in infants. Allergol Immunopathol (Madr) 2018; 46: 210-217.

2. Mallol J, García-Marcos L, Solé D, Brand P; EISL Study Group. International prevalence of recurrent wheezing during the first year of life: variability, treatment patterns and use of health resources. Thorax 2010; 65: 1004-1009. 
3. Ashley MJ, Ferrence R. Reducing children's exposure to environmental tobacco smoke in homes: issues and strategies. Tob Control 1998; 7: 61-65.

4. Di Franza JR, Aligne CA, Weitzman M. Prenatal and postnatal environmental tobacco smoke exposure and children's health. Pediatrics 2004; 113(Suppl 4): 1007-1015.

5. Willers S, Axmon A, Feyerabend C, Nielsen J, Skarping G, Skerfving S. Assesment of environmental tobacco smoke exposure in children with asthmatic symptoms by questionnaire and cotinine concentrations in plasma, saliva, and urine. J Clin Epidemiol 2000; 53: 715-721.

6. Benowitz NL. Cotinine as a biomarker of environmental tobacco smoke exposure. Epidemiol Rev 1996; 18: 188-204.

7. Zalata A, Yahia S, El-Bakary A, Elsheikha HM. Increased DNA damage in children caused by passive smoking as assessed by comet assay and oxidative stres. Mutat Res 2007; 629: 140-147.

8. Aycicek A, Ozcan E, Kocyigit A. Decreased total antioxidant capacity and increased oxidative stres in passive smoker infants and their mothers. Pediatr Int 2005; 47: 635-639.

9. Powell CV, Nash AA, Powers HJ, Primhak RA. Antioxidant status in asthma. Pediatr Pulmonol 1994; 18: 34-38.

10. Boldyrev AA, Dupin AM, Bunin AY, Babizhaev $\mathrm{MA}$, Severin SE. The antioxidative properties of carnosine, a natural histidine containing dipeptide. Biochem Int 1987; 15: 1105-1113.

11. Boldyrev AA, Aldini G, Derave W. Physiology and pathophysiology of carnosine. Physiol Rev 2013; 93: 1803-1845.

12. Tanaka KI, Kawahara M. Carnosine and lung disease. Curr Med Chem 2020; 27: 1714-1725.

13. Black PN, Scragg R. Relationship between serum 25- hydroxyvitamin D and pulmonary function in the third national health and nutrition examination survey. Chest 2005; 128: 3792-3798.

14. Jolliffe DA, Griffiths CJ, Martineau AR. Vitamin $\mathrm{D}$ in the prevention of acute respiratory infection: systematic review of clinical studies. J Steroid Biochem Mol Biol 2013; 136: 321-329.

15. Stragierowicz J, Mikolajewska K, Zawadzka-Stolarz M, Polanska K, Ligocka D. Estimation of cut off values of cotinine in urine and saliva for pregnant women in Poland. Biomed Res Int 2013; 2013: 386784.
16. Hallit S, Leynaert B, Delmas MC, et al. Wheezing phenotypes and risk factors in early life: The ELFE cohort. PLoS One 2018; 13: e0196711.

17. Martinez FD, Wright AL, Holberg CJ, Morgan WJ, Taussig LM. Maternal age as a risk factor for wheezing lower respiratory illnesses in the first year of life. Am J Epidemiol 1992; 136: 1258-1268.

18. Sherriff A, Peters TJ, Henderson J, Strachan D; ALSPAC Study Team. Avon Longitudinal Study of Parents and Children. Risk factor associations with wheezing patterns in children followed longitudinally from birth to $3(1 / 2)$ years. Int J Epidemiol 2001; 30: 1473-1484.

19. Caudri D, Savenije OEM, Smit HA, et al. Perinatal risk factors for wheezing phenotypes in the first 8 years of life. Clin Exp Allergy 2013; 43: 1395-1405.

20. Benicio MHD, Ferreira MU, Cardoso MRA, Konno SC, Monteiro CA. Wheezing conditions in early childhood: prevalence and risk factors in the city of Sao Paulo, Brazil. Bull World Health Organ 2004; 82: 516-522.

21. Demirel S, Guner SN, Celiksoy MH, Sancak R. Is vitamin $\mathrm{D}$ insufficiency to blame for recurrent wheezing? Int Forum Allergy Rhinol 2014; 4: 980985.

22. Prasad S, Rana RK, Sheth R, Mauskar AV. A hospital based study to establish the correlation between recurrent wheeze and vitamin D deficiency among children of age group less than 3 years in Indian scenario. J Clin Diagn Res 2016; 10: SC18-SC21.

23. Dogru M, Seren LP. Serum 25-hydroxyvitamin D levels in children with recurrent wheezing and relation to the phenotypes and frequency of wheezing. Eur Ann Allergy Clin Immunol 2017; 49: 257-262.

24. Peat JK, Keena V, Harakeh Z, Marks G. Parental smoking and respiratory tract infections in children. Paediatr Respir Rev 2001; 2: 207-213.

25. Lux AL, Henderson AJ, Pocock SJ. Wheeze associated with prenatal tobacco smoke exposure: a prospective, longitudinal study. ALSPAC Study Team. Arch Dis Child 2000; 83: 307-312.

26. Gilliland FD, Berhane K, Islam T. Enviromental tobacco smoke and absenteeism related to respitory illness in school children. Am J Epidemiol 2003; 157: 861-869.

27. Hofhuis W, de Jongste JC, Merkus PJ. Adverse health effects of prenatal and postnatal tobacco smoke exposure on children. Arc Dis Child 2003; 88: 1086-1090. 
28. Atay Ö, Pekcan S, Göktürk B, Özdemir M. Risk factors and clinical determinants in bronchiolitis of infancy. Turk Thorac J 2020; 21: 156-162.

29. Chen Y. Environmental tobacco smoke, low birth weight, and hospitalization for respiratory disease. Am J Respir Crit Care Med 1994; 150: 54-58.

30. Mannino DM, Caraballo R, Benowitz N, Repace J. Predictors of cotinine levels in US children: data from the Third National Health and Nutrition Examination Survey. Chest 2001; 120: 718-724.

31. Irvine L, Crombie IK, Clark RA, et al. What determines levels of passive smoking in children with asthma. Thorax 1997; 52: 766-769.
32. Willers S, Axmon A, Feyerabend C, Nielsen J, Skarping G, Skerfving S. Assessment of environmental tobacco smoke exposure in children with asthmatic symptoms by questionnaire and cotinine concentrations in plasma, saliva and urine. J Clin Epidemiol 2000; 53: 715-721.

33. Chang MY, Hogan AD, Rakes GP, et al. Salivary cotinine levels in children presenting with wheezing to an emergency department. Pediatr Pulmonol 2000; 29: 257-263. 